\title{
On Cultivation of Rhetoric Awareness in Translation Teaching
}

\author{
Guoxi Chai, Qiaozhi Wen \\ Department of foreign languages, Xijing University, Xi'an Shaanxi 710123, China
}

Keywords: Translation teaching, Rhetoric awareness, Target Language audiences.

\begin{abstract}
With era development, the society puts forward new requirements for translation talents. The cultivation of translation talents need to face the future and reality. Meanwhile, it is necessary to pay attention to training comprehensive quality. Rhetoric can effectively improve language grace and language expression accuracy, so the study on rhetoric awareness training in translation teaching is of great importance. This paper focuses on basic definition of rhetoric and target language audiences to analyze the great function of rhetoric in translation and the important significance of rhetoric awareness training in translation teaching, and proposes the measures to train rhetoric awareness in translation teaching, in the hope of helping teachers engaging in translation work.
\end{abstract}

\section{Introduction}

Nowadays, world economy is developing to integration, and cultural fusion and absorption trend is obvious. The demand for translation talents becomes increasingly large. Translation is no longer translation of ancient Chinese prose and classical books, but closely related to reality. In translation teaching process, the change of translation to facing reality happens quietly. Under the new situation, translation teaching should face the reality to train talents with outstanding comprehensive quality in order to promote cultural and economic exchange of various countries and nations and adapt special requirements of new era for translation talents. A famous ideologist in Qing Dynasty once put forward the standards of translation - "faithfulness, expressiveness and elegance". "Elegance" is to influence the target language audiences with rhetoric means. Due to cultural difference of various nations and countries, translation work should pay attention to consideration of target language audiences in the new period and avoid aggravation of national distrust due to no attention to rhetoric force. under the background of attaching importance to cultural difference, this paper expounds the importance of rhetoric and the necessity of training students' rhetoric awareness, and analyzes the measures to train students' rhetoric awareness in translation teaching.

\section{Overview of rhetoric}

\section{Brief introduction to rhetoric}

In educational circle, there is no consistent cognition on the definition of rhetoric. Various scholars understand rhetoric differently from their own perspective. A classical definition of rhetoric is to polish words and improve language expression competence in a vivid, distinct and accurate way"[1]. But, many scholars are no longer limited to the classical definition of rhetoric. They pay more attention to the research on rhetoric. Most scholars in China consider the purpose of rhetoric is to improve language expression accuracy and vividness, but foreign scholars expand the definition of rhetoric, extend the definition range of classical definition of rhetoric and regard rhetoric as a method to influence audiences' thought ${ }^{[2]}$. Rhetoric not just owns aesthetic significance, but also can provide new thought and cognitions perspective by depending on the perspective of aesthetic. The new world presented by aesthetic can effectively influence people's thought and emotion. Besides, aesthetic can improve the art of persuasion and speech and boost aesthetics of language.

\section{Relation between translation and rhetoric}

Translation is to translate the languages of other countries to the target language. In order to improve translation accuracy and vividness, rhetoric is often applied in translation. It is necessary to apply rhetoric to make the article become the symbolic language facing the audiences. Besides, 
translation like rhetoric faces realistic practical activity. For a long time, the educational circle only deems rhetoric as a means to improve literary significance of literary works in translations. The focus is the application of rhetoric. This restricts extension of rhetoric. Rhetoric not just has the function of aesthetic significance, but also can improve the cognition and comprehension ability of target language audiences and influence their thought and emotion. With economic globalization, the application of rhetoric can greatly eliminate the wide gap of cultures and gain cultural sense of identity. In current translation field, rhetoric plays a decisive role. Many scholars realize the applications characteristics of rhetoric and even believe rhetoric plays an indispensable role in life and art. On the contrary, some theories and ideological cognition of rhetorical can influence translation in turn and expand people's cognition of translation ${ }^{[3]}$. In traditional translation, scholars pay attention to faithfulness, expressiveness and elegance of translated text and ignore active thinking of target language audiences. But under the influence of rhetoric, translation pays more and more attention to culture, religion and faith differences of target language audiences. Translation is not to vividly present the significance of texts blindly, but to consider the acceptability of audiences, win the recognition degree of target language audiences for translated works and finally reach the purpose of translation.

Contemporary rhetoric considers that translation is that translators depend on the original text and apply various language tools to elaborately construct a new world. Translated works can effectively influence audiences' thought and sense of identity. Traditional translation is based on language, culture and norms. Translation practice indicates that rhetoric should serve as the entry point of translation in translation process and regard translation as the process of influencing target language audiences by using rhetorical language ${ }^{[4]}$.

\section{Measures to train rhetoric awareness in translation teaching}

The purpose of rhetors' use of rhetoric is not for indulging in self-admiration, but for establishing a relation with the audiences through using rhetoric. Audiences refer in particular to all people who want to influence others through their own language. As globalization goes deep, cultural and economic exchange of various countries becomes gradually frequent, and the realistic demand for translation becomes more and more vigorous. Hence, the study on how to influence the audiences with rhetoric in translation becomes a new focus of translation. Translators should not transfer information to target language audiences rigidly and passively, and the target language audiences should not passively participate in the translation process. In the face of the huge gap between cultures, rhetoric can be used to carry out well-grounded rhetoric transformation for the language with great controversy, improve recognition degree of audiences, eliminate cultural contradiction and motivate readers' reading interest. Therefore, teachers should train students' rhetoric awareness consciously in translation teaching process and enhance students' cognition about the importance of understanding target language audiences ${ }^{[5]}$. In translation teaching, students should deeply cognize rhetoric strength and implement the cognition of effectively influence on target language audiences with rhetoric in translation practice.

\section{Pay attention to target language audiences}

Traditional translatology holds that translation is to transform a language into another language. Language transformation process stresses aesthetic significance of texts. Translation language pursues faithfulness, expressiveness and elegance. However as the era develops, such traditional translation idea falls behind. Contemporary translatology is no longer limited to discussion on the meaning of texts, but regards translation as a kind of language exchange activity which can influence target language audiences. The relationship between the audiences and translation should not be passive participation relationship. Translation is a realistic activity with applicability. Translation must get the approval of audiences in order to give play to its function. Translation is not only the zero interaction with the audiences and the thinking restricted to translated text level. Hence, it is required to fully realize the importance of audiences in the application of rhetoric in translation process and pay attention to cultural and emotional difference of target language audiences. For example, under 
current context, we deem “Hong Kong, Macao and Taiwan” as “foreign investment”. If "Hong Kong, Macao and Taiwan" are directly translated into "foreign investment", audiences' cognition may have deviation and they consider translators deem indivisible Chinese territory - Hong Kong, Macao and Taiwan as the part independent of the People's Republic of China. This translation fully indicates translators fail to pay sufficient attention to the target language audiences and ignore cultural difference between the text and target language audiences.

Audiences' awareness should be further valued in economic activity. The economic activity aims to gain economic benefit. Hence, translators cannot simply translate texts in commercial translation process, but should adopt some rhetorical strategies to influence customers' thought, improve their recognition degree for products and finally make customers buy products willingly. For example, during translating Maxwell House “Good to the last drop”, it is translated into “滴滴香浓，意犹未 尽”. This translation is concise and readable. It can arouse people's desire to buy the coffee. The practice proves that translation is not to study aesthetic significance of texts, but a means to influence the audiences. Thus, in translation teaching process, it is required to pay attention to significance education for audiences and base translation on the target audiences.

\section{Fully recognize the importance of rhetoric}

The application of rhetoric an show more powerful strength than simple language translation of plain text. Translators use rhetoric to construct the context according to the original text, which can effectively act on the audiences and influence their thought and emotion. Sometimes, this can change audiences' attitude and finally generate the effect which conforms to translators' expectation. For instance, during translating The Bridge of Madison County, it is not literally translated, but translated into “廊桥遗梦”. Such translation not just highlights the theme of the film, but also has dense atmosphere of ancient style prose. When audiences watch the film and combine the film title, they will feel the dilemma of Francis who left his family and stayed together with Kincaid. But the ending of the story is that the love for Kincaid had to be buried in the heart.

In turn, simple text language transformation without rhetoric may aggravate cultural conflict. For example, “前沿平台” in “福建一直是对台交流的前沿平台” is translated into “frontier platform”. The audiences will form cognitive bias and understand frontier as the borderline between countries. This implies Taiwan does not belong to the People's Republic of China. Such translation will result in bad effects on audiences' psychology. If this is utilized and attacked by those with ulterior motives, the translator will be seriously damaged. “前沿平台” may be translated into “leading in” by rhetoric to avoid misunderstanding and positively influence target language audiences. Rhetoric has powerful strength in translation. If rhetoric is well applied, positive influence will be brought. If it is not used rationally, major accident may be caused. Hence, students should fully realize the great power of rhetoric and avoid bad association and feeling of target language audiences.

\section{Pay attention to "faithfulness, expressiveness and elegance" of translation and the form}

In translation process, the content and form must be noticed in order to influence audiences' thought and emotion with rhetoric. In terms of translation content, translators should try their best to reach "faithfulness, expressiveness and elegance" of contents under the preconditions of fully knowing special culture and national conditions of both countries. "Faithfulness" requires that the translated text should be accurate and convincing. "Expressiveness" requires that the translated text should be smooth and easy to remember and go deep into the mind of audiences. "Elegance" means the wording of translated text should be elegant and graceful. "Faithfulness, expressiveness and elegance" of contents require the translators take into account of native cultural characteristics and apply appropriate language which is accepted by the people. In translation teaching process, it is required to stress students' pursuit of “faithfulness, expressiveness and elegance”. Except translation content, it is also required to pay sufficient attention to translation form. Different rhetoric forms will generate different effects, so translators should choose appropriate rhetoric forms according to their expected translation objective. Different countries have different style or manner of writing. If translators are excessively restricted to traditional form, readers will generate great contradiction mentality for the translation. Thus, in translation teaching activity, teachers should consciously train 
students' cognition for the importance of translation language form. Translation should be close to reality as far as possible so that readers read fluently and naturally. Meanwhile, the style and wording are authentic. During translation, translators should use native language habits rather than mechanical copying. In this way, the article is difficult to articulate and understand.

\section{Emphasize application of reverse thinking in translation}

In translation process, translators should not cater to target language audiences blindly. To make the audiences reach the expected reading effect, translators do not always complete translation through conforming to or pleasing the audiences. By use of reverse thinking, translators take expected translation purpose as the center and choose suitable transform form and content. In the translation process, translators can skillfully use some methods to impose certain pressure on the audiences and guide them to follow translators' thought. For example, during introducing the implied meaning of Fujian (福建) to foreigners, if “福” and “建” are explained separately, foreigners” comprehension obstacle may be caused. During investigating reverse thinking the implied meaning of Fujian (福建) with reverse thinking, the translator mainly expects foreigners to feel the implied meaning of Fujian (福建) - “the place of good fortune”. Thus, in the translation, the translator should not be limited to self-concept cognition, and "the place of good fortune" can be directly translated into "Region is blessed by god in many ways". Such translation can reach the translator's expected effect, and foreigners can fully understand the connection between "Fujian" and "Region is blessed by god in many ways" [5]. Therefore, in translation teaching process, teachers should pay attention to application of reverse thinking so as to effectively achieve translators' expected objective and effectively influence the thought and emotion of target language audiences.

\section{Conclusion}

The purpose of translation teaching is to train translation talents who adapt market and social demand. Translation has the function of realistic application. So, translation practice teaching should be valued in translation teaching. The rational application of rhetoric in translation can effectively influence the thought, emotion and attitude of target language audiences. Thus, in translation teaching, it is required to focus on training students' rhetoric awareness. The author hopes more professional persons can study this topic and make contributions to training translation talents. For any omission in this paper, the author hopes professional persons can point it out.

\section{References}

[1] Tao Lichun, On training double-language and double-culture awareness in translation teaching, Oversea English, 2012, (20715):146-147.

[2] Chen Xiaowei, Trainings rhetoric awareness in translation teaching, Foreign Language Learning Theory and Practice, 2012, (13903):86-90.

[3] Feng Quangong, On translation rhetoric, Foreign Language Education, 2012, 33(15705): 100-103.

[4] Chen Xiaowei, “New rhetoric perspective” in translation studies, Fujian Normal University, 2011.

[5] Sun Xiaofeng, Overview of rhetoric teaching for teaching Chinese as a foreign language, Zhengzhou University, 2015. 